\title{
The Analysis and Research of the Runway Conflict Detection System
}

\author{
Song Weiwei \\ Department of Civil Aviation \\ Shenyang Aerospace University \\ Liaoning, China \\ e-mail: wwsong1@126.com
}

\begin{abstract}
With the increasing volume of air traffic, the workload of controllers' and pilots'continued to rise which makes the runway incursions grow rapidly and the air safety become more seriously. The runway is one of the most important maneuver area in the aircraft ground movement, as more than half of the aircraft incidences occur during the aircraft takeoff or landing stage, thus enhancing runway safety management is very important, and the research of the runway incursion detection is needed. In order to avoid runway incursions, we studied the runway conflict alerting system which based on the radar detection. This system discussed the runway conflict detection problem from the perspective of the air traffic control. Affecting factors which contain the physical properties of aircraft types, wake turbulence, radar error as well as pilot judgment and reaction time are all taking into consideration. At tht same time, this system analyzed the effect factors of runway incursions. The system used caculation between the invading aircraft and the normal aircraft, at last, it will give avoidance suggestions. It can make the crew more efficient. The simulation example shows the effectiveness of the invasion of the runway conflict detection strategies.
\end{abstract}

Keywords-runway; conflict detection; air traffic control; controller; alarm

\section{INTRODUCTION}

With the rapid growth of passenger traffic, traffic congestion occurs at many airports, runway incursions have occurred, and it has become a major security problem in today's aviation industry ${ }^{[1]}$. Runway incursion ${ }^{[2]}$ is the key for influencing the airport security. In the United States, according to statistics of FAA, airplane accidents have thirty percent is due to runway incursions from 2004 to 2006. Currently runway incursions has become an important factor affecting flight safety. In order to solve this problem, $\mathrm{NASA}^{[3]}$ developed a runway incursion prevention system, the system can display a runway, taxiways and conflict alerting on the monitor, etc; Poe ${ }^{[4]}$ developed a runway awareness and advisory system which enhanced the decision-making capacity of the crew. Zhu Xinping $^{[5]}$ was studied taxiway conflict prediction and proposed control strategy to resolve the conflict. An Hongfeng ${ }^{[6]}$ proposed an airfield taxiway lights control instruction which based on Petri nets. The analysis of the above documents are based on the assumption that the target event location information is known, no binding target position for technical analysis of relevant control problems.
Therefore, this paper presents relevant strategy under the runway conflict alerting system which based on radar detection conditions. Finally, the simulation verify the feasibility of the detection strategy.

\section{THE DEFINITION AND AFFECTING FACTORS OF THE RUNWAY INCURSIONS}

\section{A. The definition of the runway incursion}

Different countries or institutions have different definition of the runway incursions. For example, the definition of runway incursion of ICAO is that any aircraft, vehicle or person that occurred within the specified event strayed the landing and taking-off ground for the protected area in the airport. The definition of runway incursion of FAA is that in the runway environment of the airport involves all events occurred that contain ground aircraft, vehicle, person or object to taking off, ready for takeoff, landing or being prepared to land of the aircraft which have collision hazard or results in loss of required separation $^{[7]}$.

\section{B. The affecting factors of the runway incursions}

The affecting factors ${ }^{[8-9]}$ of runway incursions are generally divided into three main areas:

(1) the errors of air traffic controller;

(2) the errors of the pilot;

(3) pedestrian mismanagement and associated vehicle control mistakes in the airport.

\section{THE RELATED KNOWLEDGE INTRODUCTION OF RUNWAY CONFLICT DETECTION SYSTEM}

\section{A. Runway conflict detection zone}

In this system, the around of each runway in the airport has a corresponding runway conflict detection zone which mainly coveres the runway and its corresponding lifting belt, and it extends to near the mark of the waiting position of the taxiway. The system only for aircraft which within the conflict detection zone of the runway for conflict detection and alerting, the operation which outside of the space will not detect conflict. It has shown in Figure 1. 


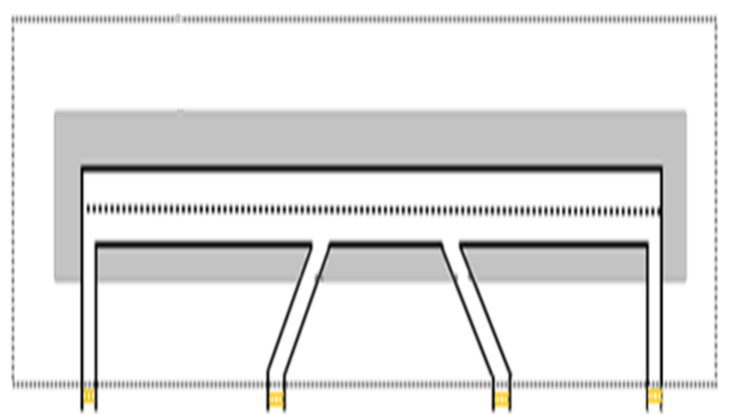

Figure 1. Runway conflict detection zone

\section{B. The principle of conflicting detection}

Conflicting detection by surface surveillance for aircraft in flight in each region to detect the position and collected the speed, type of each aircraft and other relevant information in a timely manner by the radar, this information will be entered into the database.

After the system has been obtained the speed, types of each aircraft and other information on the airport surface through a radar, and through the appropriate function to calculate the aircraft which is located at the entrance to the runway for taking-off speed analog functions and analog brake function of the aircraft in the background. When the normal operation of the aircraft which is entering the takeoff stage, the system will be according to the radar speed information of the aircraft which has been collected and the coefficients previously generated to simulate takeing-off speed function which has been corrected to give the aircraft at takeoff stage corresponding position at any time. Once the system detects a corresponding potential invasion of the aircraft to reach the boundary of the runway conflict detection zone, the system will automatically combine the radar to detect aircraft of this information to predict the speed of the aircraft according to the function in the database and to calculate when it has been at the waiting position of the taxiway and it needs to take measures to brake the aircraft into the runway, whether it can avoid conflict. If the system calculates that the aircraft was unable to stop before the conflict, then the system will issue a warning, and after the operation, it will output the recommendations to resolve the conflict.

\section{RUNWAY CONFLICT DETECTION SYSTEM STRUCTURE AND LAYOUT}

\section{A. System structure}

\section{a. Simplified mathematical functions}

According to flight performance and planning ${ }^{[10]}$, when the aircraft occurred runway incursions during taking-off, the invading aircraft and the taking-off aircraft should take appropriate measures for the first time. In the process of taking-off speed up, the relationship between the position of the aircraft on the runway and the time is approximately (L1 is the fuselage length setpoint in the database which is correspond its type):

$$
V_{L O F}=\sqrt{\frac{2 W}{C_{L O F} \cdot \rho \cdot S}}
$$

$$
L=\frac{\left(V_{L O F} \pm U\right)^{2}}{2 g\left(T / W-f^{\prime} \cdot \zeta\right)}+L_{1}
$$

After occuring the runway incursions, if the system in operation which comes to an aircraft should immediately slow down and brake in taking-off state, then the ralationshio of the position of the aircraft on the runway and the time changes are as follows:

$$
L=\frac{V_{\text {滑行 }}{ }^{2}}{2 g\left(f_{2}{ }^{\prime} \cdot \zeta_{2}-T^{\prime}{ }_{2} / W_{2}\right)}+L_{2}
$$

After the aircraft in the event of runway incursions, the system calculated the aircraft in a taxiway which should immediately slows down and brakes, the relationship between the position on the runway and time changes to:

$$
\begin{gathered}
V_{\text {识别 }}=V_{\text {探 }}+g\left(T / W-\zeta \cdot f^{\prime}\right) \cdot\left(t_{2}+t_{1}\right) \\
V_{1}=V_{\text {探 }}+g\left(T / W-\zeta \cdot f^{\prime}\right) \cdot t_{2} \\
\left.L=\frac{\left(V_{1} \pm U\right)^{2}}{2 g\left(T / W-\zeta \cdot f^{\prime}\right)}+\Delta t\left(V_{\text {识别 }} \pm U\right)+\frac{\left(V_{\text {识别 }} \pm U\right)^{2}}{2 g\left(f^{\prime \prime} \cdot \zeta-T^{\prime} / W\right.}\right)
\end{gathered}
$$


b. The process of the conflict detection algorithm

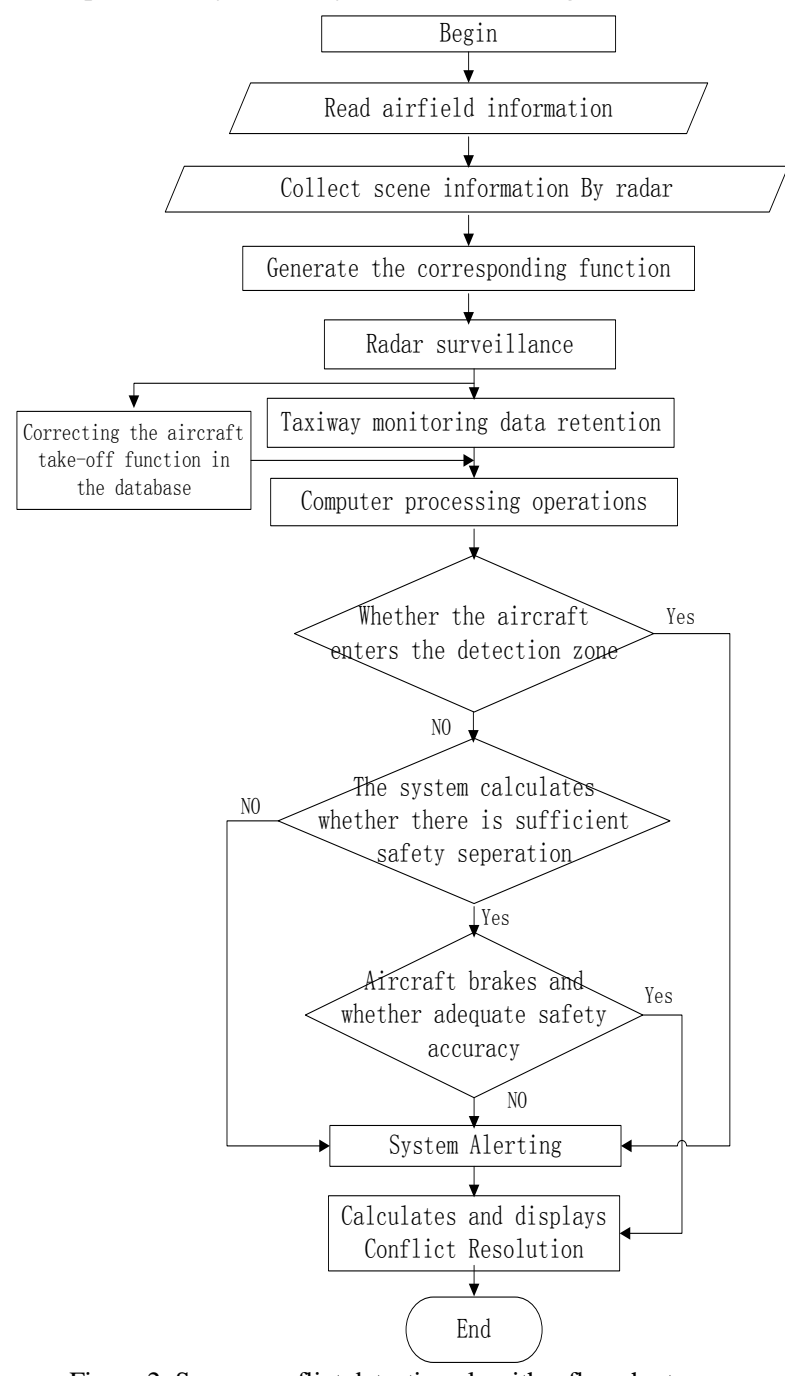

Figure 2. Scenes conflict detection algorithm flowchart

In this system, the aircraft was only regarded as "potential conflict of aircraft" is that which is only near the border of the runway intrusion detection region. The radar mainly detects conflict for the aircraft that is about to reaching the main holding position of the taxiway. Thereafter, the system filters outliers by screening module, using the remaining valid data to simulate aircraft conflict and alarm operation.

\section{B. Layout Design}

The system uses the Java programming language as the design language, mysql database, the internal procedures used java and jdbc connection to the database which in order to design a relevant conflict detection system simulation software.

When the normal operation aircraft is approaching to the runway, the situation in the event of an aircraft is about to crossing the holding position mark of the taxiway which is considered to trend and have occurred runway conflict. If the system is less than the safety distance after calculating between the normal operational aircraft and the potential conflicts aircraft, this will be ragarded as the conflict in line with the runway, the system will give warning information timely and give appropriate avoidance recommendations to air traffic controllers.

When a B747 aircraft is in the take-off process, the occurrence of a random moment in the runway conflict, the type of the conflict aircraft is A320, this time the routes of the two aircraft which cross the conflict. Alarming interface and system simulation results is shown in Figure 3.

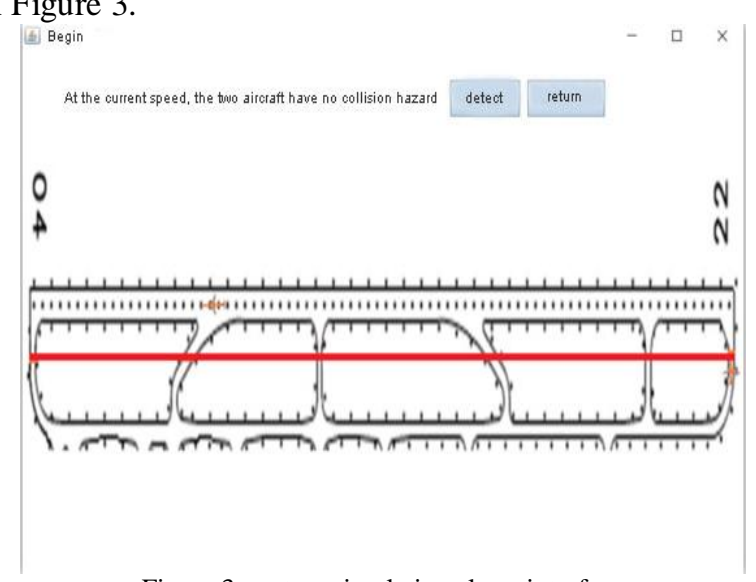

Figure 3. system simulation alarm interface

\section{CONCLUSIONS}

This paper describes a runway conflict detection system which based on radar. This system deals with higher efficiency and obvious advantages. The simulation tests show that the system can detect the conflicts in a timely manner and make alarm notification to air traffic controllers timely. Therefore, It may through effective conflict detection to protect aircraft ordered and fast running on the airport scene, culminating in a large extent, reducing air traffic controller workload and the occurrence of leakage wrong to forget and reducing the possibility of conflict on the runway fundamentally.

\section{REFERENCES}

[1] ZHANG Chao, FENG Ting, ZHENG Fu-mei. The relationship between runway incursions and transportation volume of civil aviation passengers and precautions. Value Engineering,19-21.

[2] Xiao Chan. Runway incursion prevention research. Technological Innovation, 2011: 163.

[3] Jones DR, Quach CC, Young SD. Runway inCursion prevention system-demonstration and testing at the Dallas/Fort Worth

International Airport[C]//Digital Avionics Systems, 2001.DASC, 20th Conference. Daytona Beach, FL, USA:IEEE,2001.

[4] Poe,Conner JJ,Gremmert KJ,etal. Ground Operations and advanced runway awareness and advisiory system: US, Wo/2005/114613[P]. 2005.

[5] ZHU Xin-ping, TANG XIN-min, HAN SONG-chen. A-SMGCS taxiway avoid conflict prediction and control[J]. Nanjing University of Aeronautics and Astronautics, 2011,43 (4): 504-510. 
[6] AN Hong-feng, TANG Xin-min, ZHU Xin-ping, ,etal.. Based on taxiway aids to navigation light control Petri Net [J]. Traffic Information and Safety, 2011,29 (4): 28-32.

[7] FAA Runway safety. Report,2005.

[8] MEI Jun-fei. Research airport runway incursion risk warning model[D]. Wuhan University of Technology,2013.
[9] HE Xiao-wei. The research of the intrusion detection algorithm of runway[J]. Journal of Civil Aviation Flight College of China,2012,23(3):35-38.

[10] LIU Xiao-ming, SU Bin, SUN Hong. Flight performance and planning[M]. Chengdu: Southwest Jiaotong University Press, 2003. 